\title{
Non-contiguous finished genome sequence and description of Kallipyga massiliensis gen. nov., sp. nov., a new member of the family Clostridiales Incertae Sedis XI
}

\author{
Perrine Hugon ${ }^{1 *}$, Dhamodharan Ramasamy ${ }^{1 *}$, Catherine Robert ${ }^{1}$, Carine Couderc ${ }^{1}$, Didier \\ Raoult ${ }^{1}$ and Pierre-Edouard Fournier ${ }^{1} \mathrm{q}$ \\ ${ }^{1}$ Aix-Marseille Université, Faculté de médecine, Marseille, France \\ *Correspondence: (pierre-edouard.fournier@univmed.fr) \\ Keywords: Kallipyga massiliensis, genome, culturomics, taxonogenomics \\ Kallipyga massiliensis strain ph $2^{\top}$ is the type strain of Kallipyga massiliensis gen. nov., sp. nov., \\ the type species of the new genus Kallipyga within the family Clostridiales Incertae Sedis XI. \\ This strain, whose genome is described here, was isolated from the fecal flora of a 26-year- \\ old woman suffering from morbid obesity. K. massiliensis is an obligate anaerobic coccus. \\ Here we describe the features of this organism, together with the complete genome sequence \\ and annotation. The $1,770,679$ bp long genome (1 chromosome but no plasmid) contains \\ 1,575 protein-coding and 50 RNA genes, including 4 rRNA genes.
}

\section{Introduction}

Kallipyga massiliensis strain ph2 ${ }^{\mathrm{T}}$ (CSUR=P241, $\mathrm{DSM}=26229$ ) is the type strain of $K$. massiliensis gen. nov., sp. nov. This bacterium was isolated from the stool sample of an obese French patient as part of a study aiming at individually cultivating all species occurring within human feces [1-3]. It is a Gram-positive, anaerobic, indole-negative coccus. Defining the taxonomic status of bacterial isolates remains a challenging task. The taxonomic molecular tools currently available, including $16 \mathrm{~S}$ rRNA sequence similarity, $\mathrm{G}+\mathrm{C}$ content and DNADNA hybridization (DDH) [4,5], although considered as gold standards, have limitations $[6,7]$. The $16 S$ rRNA sequence similarity and $G+C$ content thresholds do not apply uniformly to all species or genera, and the DDH method lacks intra- and inter-laboratory reproducibility [5]. The advent of high-throughput genome sequencing and proteomic analysis [8] has granted unprecedented access to exhaustive genetic and protein information for bacterial isolates. We recently proposed a polyphasic approach to describe new bacterial species in which genome sequences and MALDITOF spectra are used along with phenotypic characteristics [9-30].

The family Clostridiales Incertae Sedis XI (Garrity and Holt 2001) was created in 2001 [31] and currently includes the 11 following genera: Anaerococcus (Ezaki et al. 2001) [32], Dethiosulfatibacter (Takii et al. 2007) [33],
Finegoldia (Murdoch and Shah 2000) [34], Gallicola (Ezaki et al. 2001) [32], Helcococcus (Collins et al. 1993) [35], Parvimonas (Tindall and Euzéby 2006) [36], Peptoniphilus (Ezaki et al. 2001) [32], Sedimentibacter (Breitenstein et al. 2002) [37], Soehngenia (Parshina et al. 2003) [38], Sporanaerobacter (Hernandez-Eugenio et al. 2002) [39] and Tissierella (Collins and Shah 1986) [40]. Currently, 31 species with validly published names are reported in this family [41]. The species listed in the Clostridiales Incertae Sedis XI are mostly comprised of Gram-positive, obligate anaerobic cocci. Members belonging to this family were identified as pathogens in both humans and animals. In humans, they were often isolated from patients with septic arthritis, necrotizing pneumonia, prosthetic joint infection and other clinical conditions associated with vaginal discharges and ovarian, peritoneal and sacral abscesses [42-46].

Here we present a summary classification and a set of features for $K$. massiliensis gen. nov., sp. nov., strain ph2 ${ }^{\mathrm{T}}$ (CSUR=P241, DSM=26229) together with the description of the complete genomic sequencing and annotation. These characteristics support the circumscription of the genus Kallipyga and its type species, $K$. massiliensis within the Clostridiales Incertae Sedis XI family. 


\section{Classification and features}

A stool sample was collected from a 26-year-old woman living in Marseille (France). She suffered from morbid obesity and had a body mass index of 48.2 (118.8 kg, 1.57 meter). At the time of stool sample collection she did not take any medication and was not on a diet. The patient gave an informed and signed consent, and the agreement of the ethics committee of the Institut Fédératif de Recherche (IFR48, Faculty of Medicine, Marseille, France) was obtained under reference 09-022. Another four new bacterial species, Alistipes obesi, Peptoniphilus grossensis, P. obesi and Enorma massiliensis [25$27,33]$, were also isolated from this specimen using various culture conditions. The fecal specimen was preserved at $-80^{\circ} \mathrm{C}$ after collection. Strain ph2 $\mathrm{T}$ (Table 1) was isolated in 2011 by anaerobic culture on 5\% sheep blood-enriched agar in anaerobic atmosphere at $37^{\circ} \mathrm{C}$, following 26 days in a blood culture bottle with rumen and sheep blood. The $16 \mathrm{~S}$ rRNA nucleotide sequence (GenBank accession number JN837487) of Kallipyga massiliensis strain ph2 ${ }^{\mathrm{T}}$ was $86.09 \%$ similar to Helcococcus sueciensis, the phylogenetically closest species (Figure 1). This value was lower than the $95.0 \%$ 16S rRNA gene sequence threshold recommended by Stackebrandt and Ebers (2006) to delineate a new genus without carrying out DNA-DNA hybridization [5].

Table 1. Classification and general features of Kallipyga massiliensis strain ph $2^{\top}$ according to the MIGS recommendations [45].

\begin{tabular}{|c|c|c|c|}
\hline MIGS ID & Property & Term & Evidence code $^{\mathrm{a}}$ \\
\hline & \multirow{8}{*}{ Current classification } & Domain Bacteria & TAS [47] \\
\hline & & Phylum Firmicutes & TAS [48-50] \\
\hline & & Class Clostridia & TAS $[51,52]$ \\
\hline & & Order Clostridiales & TAS $[53,54]$ \\
\hline & & Family Clostridiales Incertae Sedis XI & TAS [55] \\
\hline & & Genus Kallipyga & IDA \\
\hline & & Species Kallipyga massiliensis & IDA \\
\hline & & Type strain ph2 ${ }^{\top}$ & IDA \\
\hline & Gram stain & Positive & IDA \\
\hline & Cell shape & Cocci & IDA \\
\hline & Motility & Non-motile & IDA \\
\hline & Sporulation & Non-sporulating & IDA \\
\hline & Temperature range & Mesophile & IDA \\
\hline & Optimum temperature & $37^{\circ} \mathrm{C}$ & IDA \\
\hline MIGS-6.3 & Salinity & unknown & IDA \\
\hline \multirow[t]{3}{*}{ MIGS-22 } & Oxygen requirement & Anaerobic & IDA \\
\hline & Carbon source & Unknown & NAS \\
\hline & Energy source & Unknown & NAS \\
\hline MIGS-6 & Habitat & Human gut & IDA \\
\hline \multirow[t]{3}{*}{ MIGS-15 } & Biotic relationship & Free living & IDA \\
\hline & Pathogenicity & Unknown & \\
\hline & Biosafety level & 2 & \\
\hline MIGS-14 & Isolation & Human feces & NAS \\
\hline MIGS-4 & Geographic location & France & IDA \\
\hline MIGS-5 & Sample collection time & January 2011 & IDA \\
\hline MIGS-4.1 & Latitude & 43.296482 & IDA \\
\hline MIGS-4.1 & Longitude & 5.36978 & IDA \\
\hline MIGS-4.3 & Depth & Surface & IDA \\
\hline MIGS-4.4 & Altitude & $0 \mathrm{~m}$ above sea level & IDA \\
\hline
\end{tabular}

Evidence codes - IDA: Inferred from Direct Assay; TAS: Traceable Author Statement (i.e., a direct report exists in the literature); NAS: Non-traceable Author Statement (i.e., not directly observed for the living, isolated sample, but based on a generally accepted property for the species, or anecdotal evidence). These evidence codes are from the Gene Ontology project [56]. If the evidence is IDA, then the property was directly observed for a live isolate by one of the authors or an expert mentioned in the acknowledgements. 


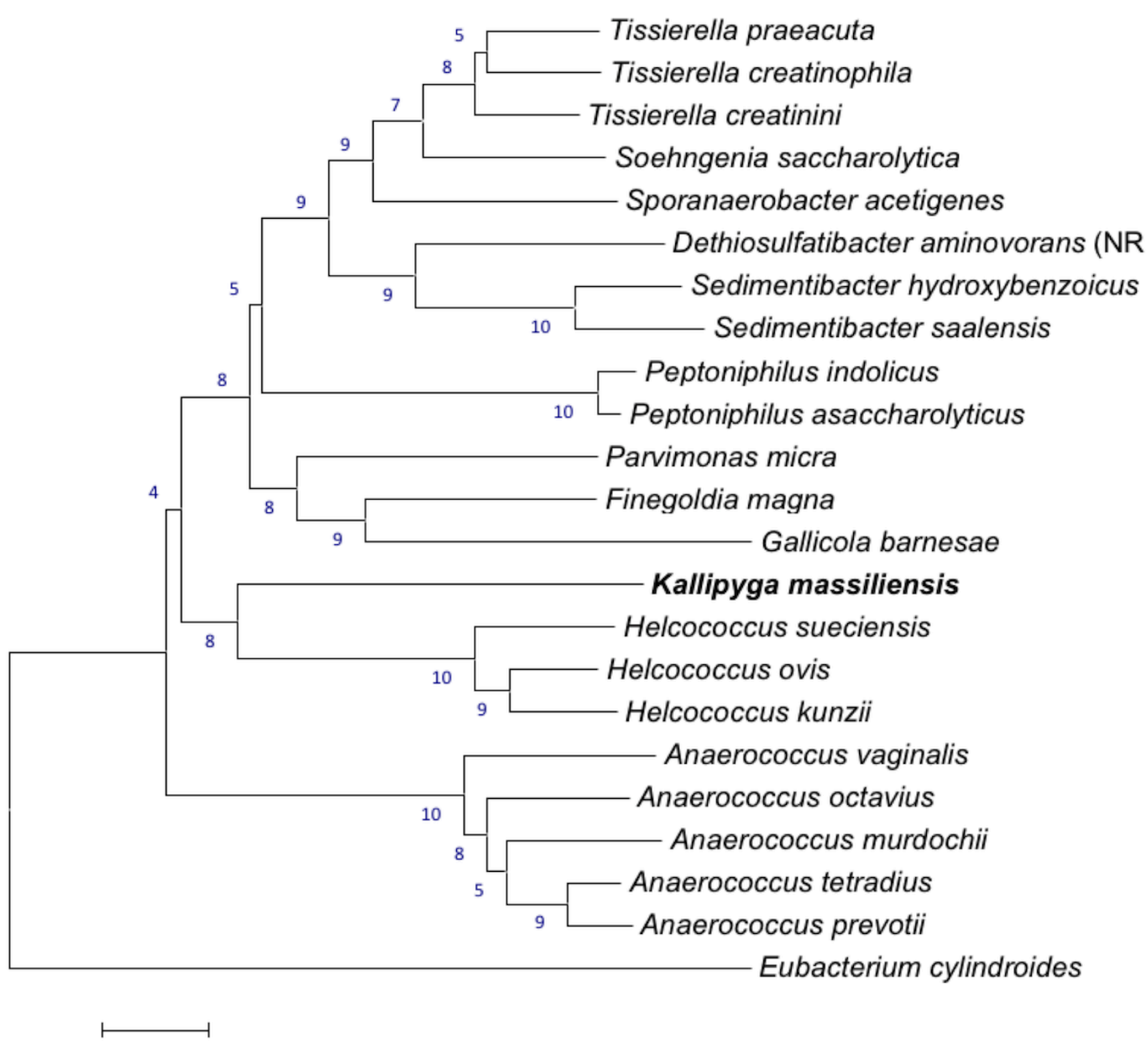

Figure 1. Phylogenetic tree highlighting the position of Kallipyga massiliensis strain $\mathrm{ph} 2^{\top}$ relative to other type strains within the Clostridiales Incertae Sedis XI family. Genbank accession numbers are indicated in parentheses. Sequences were aligned using CLUSTALW, and phylogenetic inferences obtained using the maximum-likelihood method in MEGA software. Numbers at the nodes are percentages of bootstrap values obtained by repeating the analysis 500 times to generate a majority consensus tree. Eubacterium cylindroides was used as outgroup. The scale bar represents a $2 \%$ nucleotide sequence divergence.

By comparison to the Genbank database [57], strain ph2 ${ }^{\mathrm{T}}$ also exhibited a nucleotide sequence similarity greater than $98.7 \%$ with 16 sequences from uncultured bacteria from the human skin microbiome [58]. These bacteria are most likely classified within the same species as strain ph2 ${ }^{\mathrm{T}}$.

Different growth temperatures $\left(25,30,37,45^{\circ} \mathrm{C}\right)$ were tested; no growth occurred at $25^{\circ} \mathrm{C}$ and $30^{\circ} \mathrm{C}$, growth occurred between $37^{\circ} \mathrm{C}$ and $45^{\circ} \mathrm{C}$, and optimal growth was observed at $37^{\circ} \mathrm{C}$. Colonies were bright grey with a diameter of $1.0 \mathrm{~mm}$ on $5 \%$ blood-enriched Columbia agar. Growth of the strain was tested under anaerobic and microaerophilic conditions using GENbag anaer and GENbag microaer systems, respectively (BioMérieux), and in the presence of air, with or without $5 \% \mathrm{CO}_{2}$. Optimal growth was obtained anaerobically. No growth was observed under aerobic and microaerophilic conditions. Gram staining showed Gram-positive cocci (Figure 2). A motility test was negative. Cells grown on agar are Gram-positive, have a diameter in electron microscopy ranging from $0.57 \mu \mathrm{m}$ to $0.78 \mu \mathrm{m}$ (mean, $0.67 \mu \mathrm{m}$, Figure 3 ) and are mostly grouped in pairs, short chains or small clumps. 


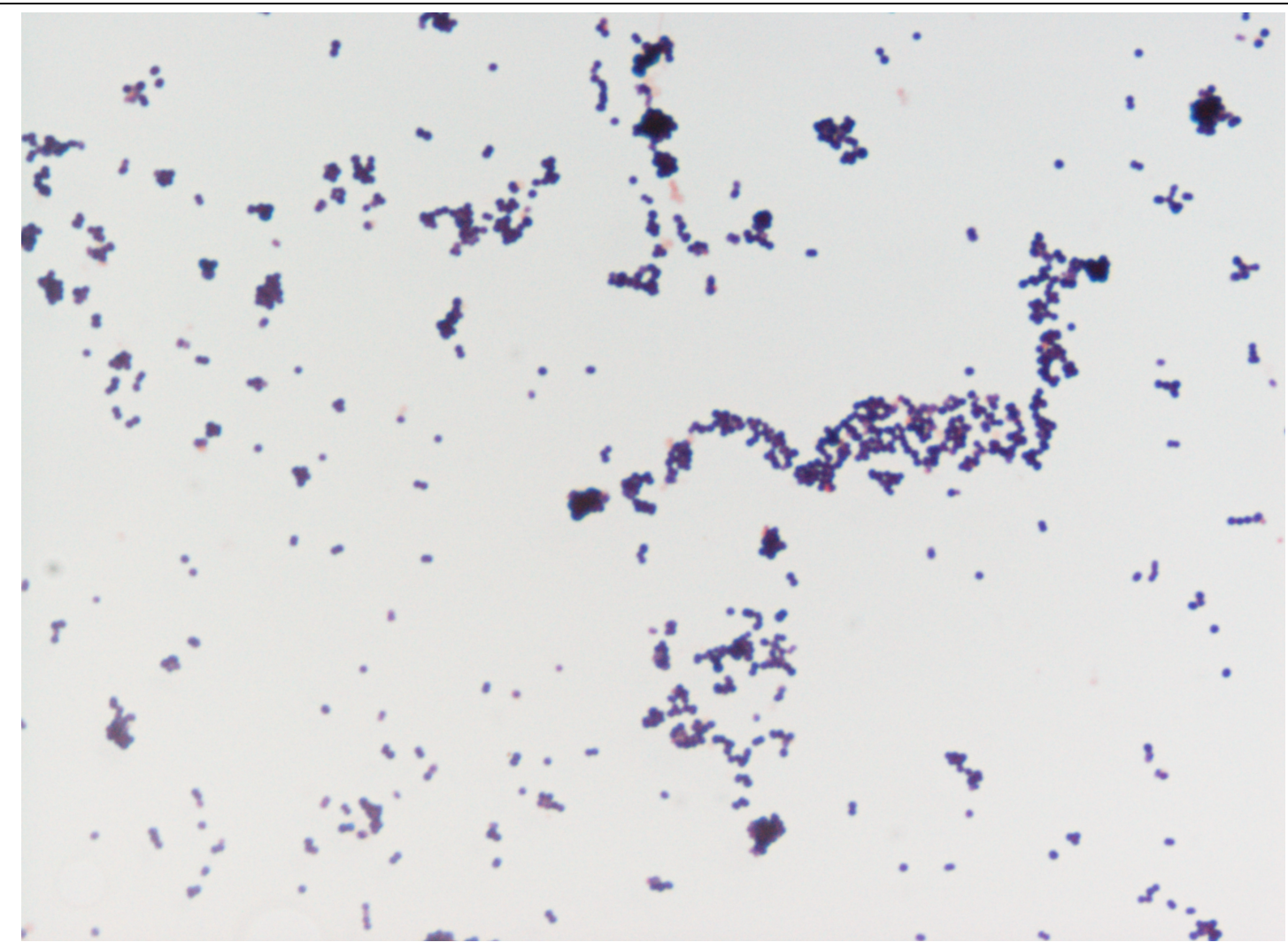

Figure 2. Gram staining of $K$ massiliensis strain $p h 2^{\top}$

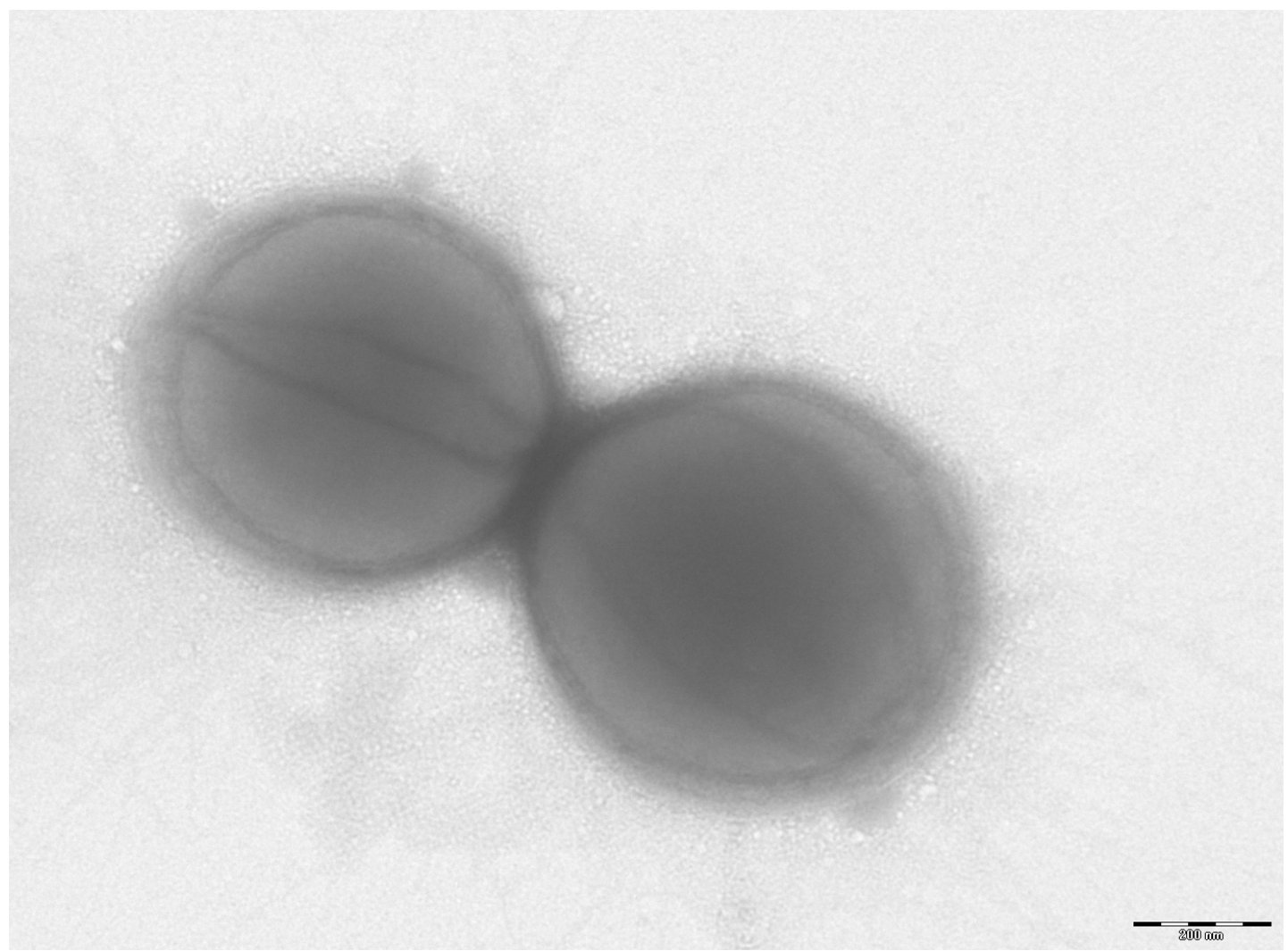

Figure 3. Transmission electron microscopy of $K$. massiliensis strain $\mathrm{ph}^{\top}$ using a Morgani $268 \mathrm{D}$ (Philips) at an operating voltage of 60kV. The scale bar represents $200 \mathrm{~nm}$. 
Strain ph2 ${ }^{\mathrm{T}}$ exhibited neither catalase or oxidase activities. Using API 32A (BioMerieux), nitrate reduction, indole formation and urease production were negative. A positive reaction was obtained for $\alpha$-galactosidase, arginine dihydrolase and arginine arylamidase, $\alpha$-glucosidase and $\beta$-glucosidase. Strain ph2 ${ }^{\mathrm{T}}$ did not ferment mannose or raffinose. Negative reactions were observed for $\beta$-galactosidase, $\beta$ galactosidase- 6 -phosphate, $\alpha$-arabinosidase, $\quad \beta$ glucuronidase, $\mathrm{N}$-acetyl- $\beta$-glucosaminidase, glutamic acid decarboxylase, proline arylamidase, leucyl glycine arylamidase, phenylalanine arylamidase, pyroglutamic acid arylamidase, tyrosine arylamidase, alanine arylamidase, glycine arylamidase, histidine arylamidase, glutamyl glutamic acid arylamidase, and serine arylamidase. Using an API Zym (BioMerieux), positive reactions were observed for esterase lipase, leucine arylamidase, $\alpha$-glucosidase, $\beta$-glucosidase and acid phosphatase. Negative reactions were obtained for esterase, lipase, valine and cysteine arylamidase, trypsine, $\quad \alpha$-chymotrypsine, naphthol-AS-BIphosphohydrolase, $\alpha$-galactosidase, $\beta$-galactosidase, $\beta$-glucuronidase, $\quad \mathrm{N}$-acetyl- $\beta$-glucosaminidase, $\alpha$ mannosidase and $\alpha$-fucosidase. Using an API $50 \mathrm{CH}$ (BioMerieux), K. massiliensis weakly fermented Dribose, D-glucose, D-fructose and aesculin. By comparison with its closest phylogenetic neighbors, $K$. massiliensis differed from Finegoldia magna in $\alpha$ galactosidase and $\alpha$-glucosidase production, $\mathrm{D}$ ribose and D-fructose fermentation. It also differed from Helcococcus kunzii in oxygen requirement, $\alpha$ galactosidase and leucine arylamidase production, D-ribose, D-glucose and esculin utilization. It differed from Parvimonas micra in alkaline phosphatase, glutamyl glutamic acid arylamidase, $\beta$ glucosidase, phenylalanine arylamidase and histidine arylamidase production and D-glucose fermentation. It differed from Peptoniphilus indolicus in $\alpha$-galactosidase, indole, $\alpha$-glucosidase, $\beta$ glucosidase, dihydrolase phenylalanine, phenylalanine arylamidase and histidine arylamidase production, and D-glucose fermentation (Table 2).

$K$. massiliensis is susceptible to amoxicillin, amoxicillin-clavulanic acid, gentamicin 500, penicillin, imipenem, vancomycin, rifampicin and nitrofurantoin, but resistant to ciprofloxacin, metronidazole, gentamicin 10, trimethoprim/sulfamethoxazole, ceftriaxon, erythromycin and doxycycline.

Matrix-assisted laser-desorption/ionization timeof-flight (MALDI-TOF) MS protein analysis was carried out as previously described [59] using a Microflex spectrometer (Bruker Daltonics, Germany). Twelve distinct deposits were done for strain ph2 ${ }^{\mathrm{T}}$ from 12 isolated colonies. The twelve ph2 ${ }^{\mathrm{T}}$ spectra were imported into our database and compared to spectra from 3,769 bacteria using the MALDI BioTyper software (version 2.0, Bruker). A score enabled the presumptive identification and discrimination of the tested species from those in a database: a score $\geq 2$ with a validly published species enabled the identification at the species level; a score $\geq 1.7$ but $<2$ enabled the identification at the genus level; and a score $<1.7$ did not enable any identification. For strain ph2 ${ }^{\mathrm{T}}$, no significant score was obtained, suggesting that our isolate was not a member of any known species or genus (Figures 4 and 5). A broader study incorporating MALDI-TOF and $16 \mathrm{~S}$ rDNA and genomic DNA identity data may be conducted to define taxonomic criteria at the family level.

\section{Genome sequencing information Genome project history}

The organism was selected for sequencing on the basis of its phylogenetic position and 16S rRNA similarity to members of the family Clostridiales Incertae Sedis XI and is part of a study of the human digestive flora aiming at isolating all bacterial species within human feces [1-3]. It was the thirty-sixth genome from the family Clostridiales Incertae Sedis XI to be sequenced and the first genome of $K$. massiliensis gen. nov., sp. nov. The GenBank accession number is CAHC00000000 and consists of 22 contigs. Table 3 shows the project information and its association with MIGS version 2.0 compliance [60].

\section{Growth conditions and DNA isolation}

Kallipyga massiliensis gen. nov., sp. nov., strain ph2 ${ }^{\mathrm{T}}$ (CSUR= P241, DSM=26229) was grown anaerobically on $5 \%$ sheep blood-enriched Columbia agar at $37^{\circ} \mathrm{C}$. Three petri dishes were spread and the bacteria cultivated were resuspended in $3 \times 100 \mu \mathrm{l}$ of G2 buffer (EZ1 DNA Tissue kit, Qiagen). A first mechanical lysis was performed by glass powder on the Fastprep-24 device (MP Biomedicals, USA) using $2 \times 20$ seconds cycles. DNA was then treated with $2.5 \mu \mathrm{g} / \mu \mathrm{L}$ lysozyme for 30 minutes at $37^{\circ} \mathrm{C}$ and extracted using the BioRobot EZ1 Advanced XL (Qiagen). The DNA was then concentrated and purified on a QIAamp kit (Qiagen). The yield and concentration was measured by the Quant-it Picogreen kit (Invitrogen) on the Genios Tecan fluorometer at $78.2 \mathrm{ng} / \mu \mathrm{l}$. 
Hugon et al.

Table 2. Differential characteristics of Kallipyga massiliensis gen. nov., sp. nov., strain ph2 ${ }^{\top}$, Finegoldia magna strain ATCC 29328, Helcococcus kunzii strain ATCC 51366, Parvimonas micra strain ATCC 33270 and Peptoniphilus indolicus strain ATCC $29427^{\top}$.

\begin{tabular}{|c|c|c|c|c|c|}
\hline Properties & K. massiliensis & F. magna & H. kunzii & P. micra & P. indolicus \\
\hline Cell diameter $(\mu \mathrm{m})$ & 0.67 & na & na & $0.3-0.7$ & na \\
\hline Oxygen requirement & anaerobic & anaerobic & facultative anaerobic & anaerobic & anaerobic \\
\hline Colony color & bright gray & var & & na & na \\
\hline Gram stain & + & + & + & + & + \\
\hline Salt requirement & - & na & $+/-$ & na & - \\
\hline Motility & - & - & - & na & - \\
\hline Endospore formation & - & - & na & na & - \\
\hline \multicolumn{6}{|l|}{ Production of } \\
\hline Alkaline Phosphatase & - & $+/-$ & - & + & - \\
\hline Catalase & - & $+/-$ & - & na & na \\
\hline Oxidase & - & na & na & na & na \\
\hline Nitrate reductase & - & - & - & na & na \\
\hline Urease & - & - & na & na & - \\
\hline$\alpha$-galactosidase & + & - & - & na & - \\
\hline$\beta$-galactosidase & - & - & - & na & - \\
\hline Indole & - & - & na & - & + \\
\hline Arginine arylamidase & + & + & na & + & + \\
\hline $\begin{array}{l}\text { Glutamyl glutamic acid } \\
\text { arylamidase }\end{array}$ & - & na & na & + & na \\
\hline Arginine dihydrolase & + & $+/-$ & na & na & - \\
\hline$\alpha$-glucosidase & + & - & na & na & - \\
\hline$\beta$-glucosidase & + & na & na & - & - \\
\hline$\beta$-glucuronidase & - & - & - & na & na \\
\hline Phenylalanine arylamidase & - & - & na & + & + \\
\hline Esterase lipase & + & na & na & na & na \\
\hline Leucine arylamidase & + & + & - & na & + \\
\hline Cystine arylamidase & - & na & na & na & na \\
\hline Histidine arylamidase & - & $-/ w$ & na & + & + \\
\hline \multicolumn{6}{|l|}{ Fermentation of } \\
\hline D-mannose & - & - & na & na & - \\
\hline D-ribose & w & - & - & na & na \\
\hline D-glucose & w & $-/ w$ & - & - & - \\
\hline D-fructose & w & + & na & na & na \\
\hline Esculin & w & na & + & na & na \\
\hline Isolated from & human gut & human & human & human & $\begin{array}{l}\text { mastitis of } \\
\text { cattle }\end{array}$ \\
\hline
\end{tabular}

na $=$ data not available; $v a r=$ variable; $\mathrm{w}=$ weak 


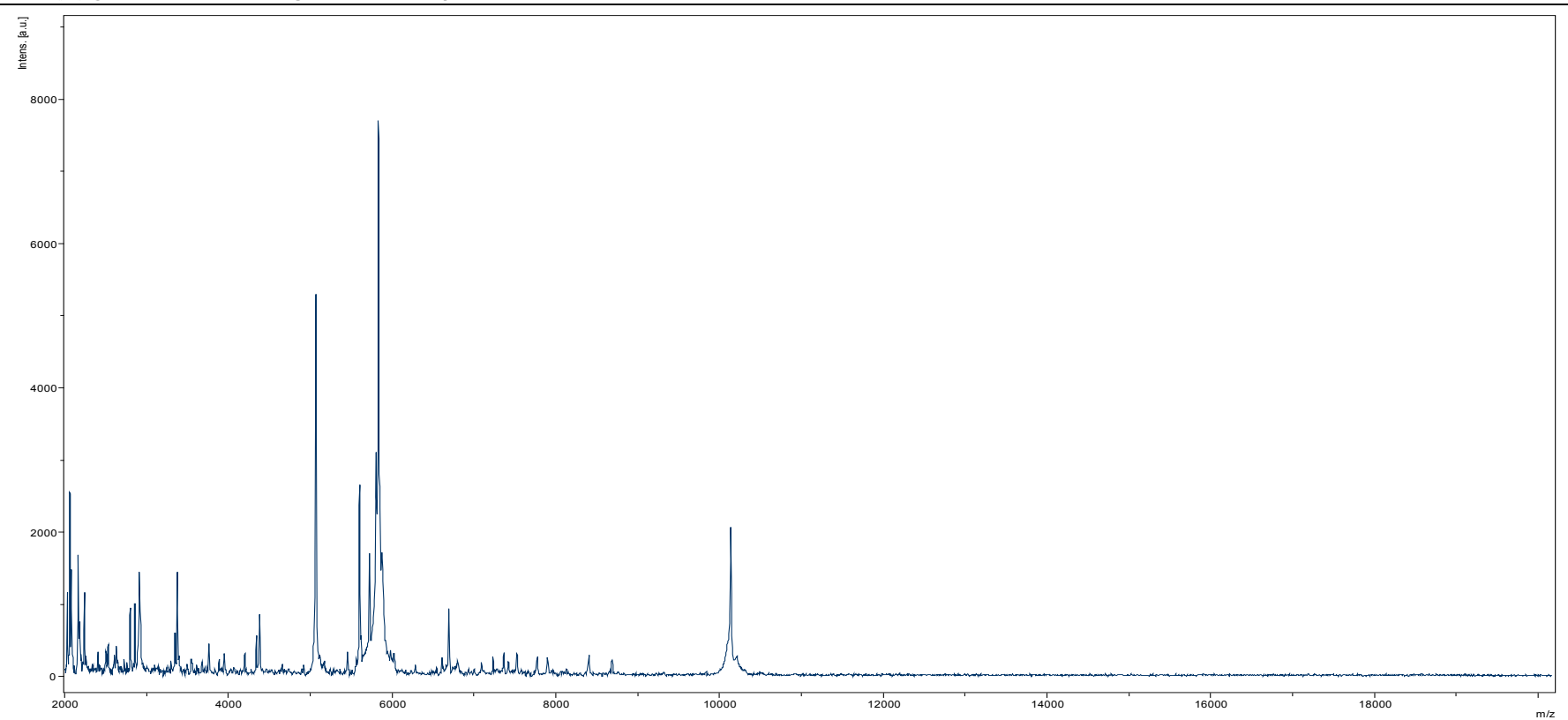

Figure 4. Reference mass spectrum from $K$. massiliensis strain $p h 2^{\top}$. Spectra from 12 individual colonies were compared and a reference spectrum was generated.

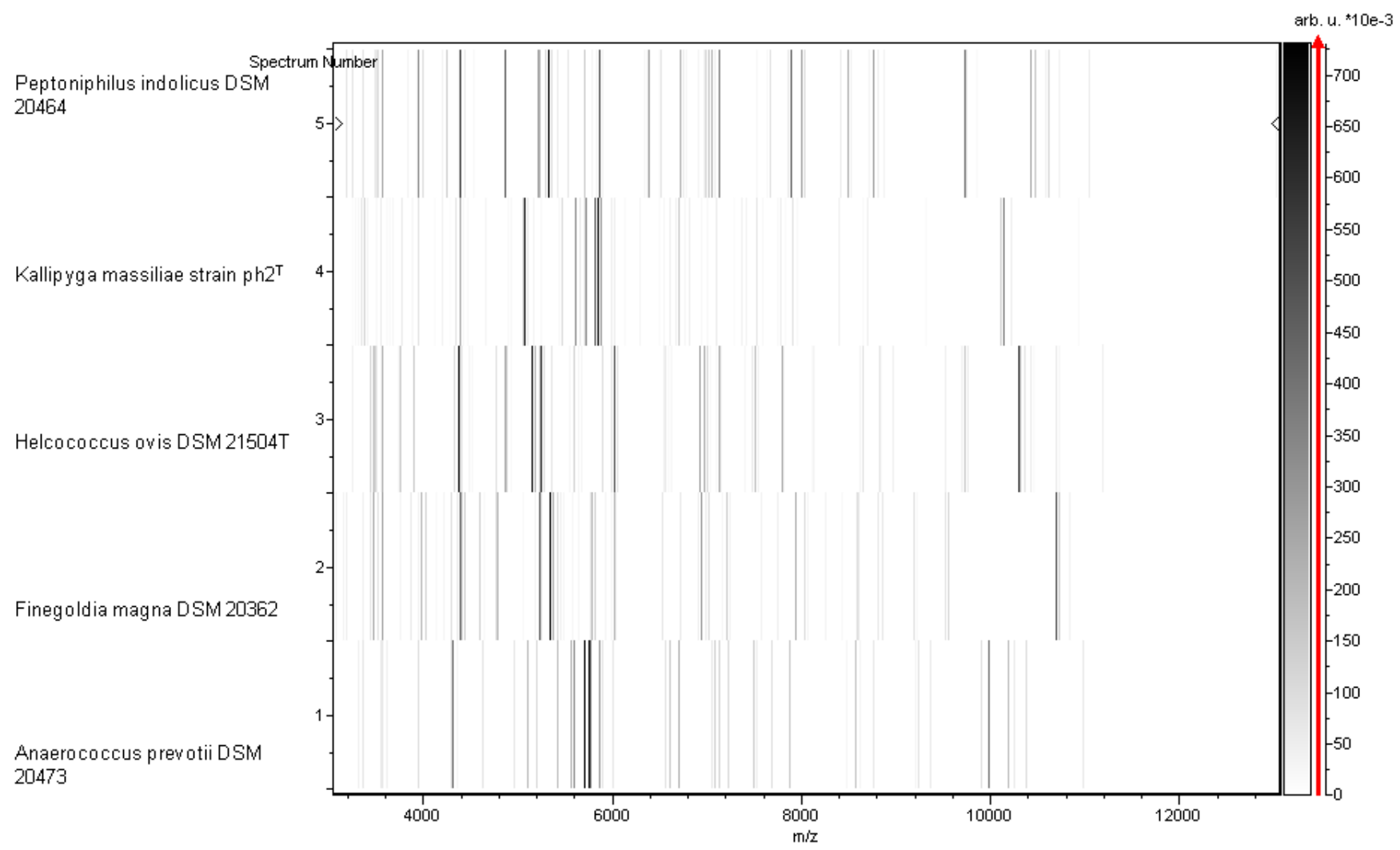

Figure 5. Gel view comparing Kallipyga massiliensis sp. nov strain $p h 2^{\top}$ to other phylogenetically close species. The gel view displays the raw spectra of loaded spectrum files arranged in a pseudo-gel like look. The $x$-axis records the $\mathrm{m} / \mathrm{z}$ value. The left $y$-axis displays the running spectrum number originating from subsequent spectra loading. The peak intensity is expressed by a Gray scale scheme code. The color bar and the right y-axis indicate the relation between the color a peak is displayed with and the peak intensity in arbitrary units. Displayed species are indicated on the left. 
Table 3. Project information

\begin{tabular}{lll}
\hline MIGS ID & Property & Term \\
\hline MIGS-31 & Finishing quality & High-quality draft \\
MIGS-28 & Libraries used & 454 GS paired-end 3- kb libraries \\
MIGS-29 & Sequencing platform & 454 GS FLX Titanium \\
MIGS-31.2 & Sequencing coverage & $51.23 \times$ \\
MIGS-30 & Assemblers & Newbler \\
MIGS-32 & Gene calling method & Prodigal \\
& Genbank Date of Release & May 30, 2012 \\
& NCBI project ID & CAHC00000000 \\
MIGS-13 & Project relevance & Study of the human gut microbiome \\
\hline
\end{tabular}

\section{Genome sequencing and assembly}

DNA (5 $\mu \mathrm{g}$ ) was mechanically fragmented on a Hydroshear device (Digilab, Holliston, MA, USA) with an enrichment size at 3-4kb. The DNA fragmentation was visualized through the Agilent 2100 BioAnalyzer on a DNA labchip 7500 with an optimal size of $3.179 \mathrm{~kb}$. A $3 \mathrm{~kb}$ paired-end library was constructed according to the 454 GS FLX Titanium paired-end protocol (Roche). Circularization and nebulization were performed and generated a pattern with an optimal at $600 \mathrm{bp}$. After PCR amplification through 17 cycles followed by double size selection, the single stranded pairedend library was quantified on the Quant-it Ribogreen kit (Invitrogen) on the Genios Tecan fluorometer at $58 \mathrm{pg} / \mu \mathrm{L}$. The library concentration equivalence was calculated as $1.77 \mathrm{E}+08 \mathrm{~mol}-$ ecules $/ \mu \mathrm{L}$. The library was stored at $-20^{\circ} \mathrm{C}$ until further use.

The paired-end library was clonally amplified with $0.5 \mathrm{cpb}$ and $1 \mathrm{cbp}$ in 2 SV-emPCR reactions with the GS Titanium SV emPCR Kit (Lib-L) v2 (Roche). The yields of the emPCR were essentially the same at 12.3 and $12 \%$, in the range of 5 to $20 \%$ recommended by the Roche procedure.

Approximately 790,000 beads were loaded on $1 / 4$ region of a GS Titanium PicoTiterPlate PTP Kit $70 \times 75$ and sequenced with the GS FLX Titanium Sequencing Kit XLR70 (Roche). The run was performed overnight and then analyzed on the cluster through the gsRunBrowser and gsAssembler (Roche). A total, of 261,794 passed filter wells were obtained and generated $90.68 \mathrm{Mb}$ with a length average of $346 \mathrm{bp}$. The global passed filter sequences were assembled using Newbler with $90 \%$ identity and $40 \mathrm{bp}$ as overlap. The final assembly identified 3 scaffolds and 22 large contigs
$(>1,500 \mathrm{bp}$ ) generating a genome size of $1.77 \mathrm{Mb}$ which corresponds to a coverage of $51.23 \times$ genome equivalent.

\section{Genome annotation}

Open Reading Frames (ORFs) were predicted using Prodigal [61] with default parameters. However, the predicted ORFs were excluded if they spanned a sequencing gap region. The predicted bacterial protein sequences were searched against the GenBank [57] and Clusters of Orthologous Groups (COG) databases using BLASTP. The tRNAs and rRNAs were predicted using the tRNAScan-SE [62] and RNAmmer [63] tools, respectively. Lipoprotein signal peptides and numbers of transmembrane helices were predicted using SignalP [64] and TMHMM [65], respectively. ORFans were identified if their BLASTP $E$-value was lower than 1e-03 for alignment length greater than 80 amino acids. If alignment lengths were smaller than 80 amino acids, we used an $E$-value of $1 \mathrm{e}-05$. Such parameter thresholds have already been used in previous works to define ORFans. Artemis [66] and DNA Plotter [67] were used for data management and visualization of genomic features, respectively. Mauve alignment tool (version 2.3.1) was used for multiple genomic sequence alignment [68]. To estimate the mean level of nucleotide sequence similarity at the genome level between $K$. massiliensis and four other members of the family Clostridiales Incertae Sedis XI (Table 6), orthologous proteins were detected using the Proteinortho software [69] and genomes compared two by two. For each pair of genomes, we determined the mean percentage of nucleotide sequence identity among orthologous ORFs using BLASTn. 


\section{Genome properties}

The genome is $1,770,679$ bp long (one chromosome, no plasmid) with a $\mathrm{G}+\mathrm{C}$ content of $51.40 \%$ (Figure 6 and Table 4). Of the 1,625 predicted chromosomal genes, 1,575 were protein-coding genes and 50 were RNAs. A total of 1,238 genes
(76.18\%) were assigned a putative function. Forty-two genes were identified as ORFans (2.66\%) and the remaining genes were annotated as hypothetical proteins. The properties and statistics of the genome are summarized in Tables 4 and 5 . The distribution of genes into COGs functional categories is presented in Table 5.

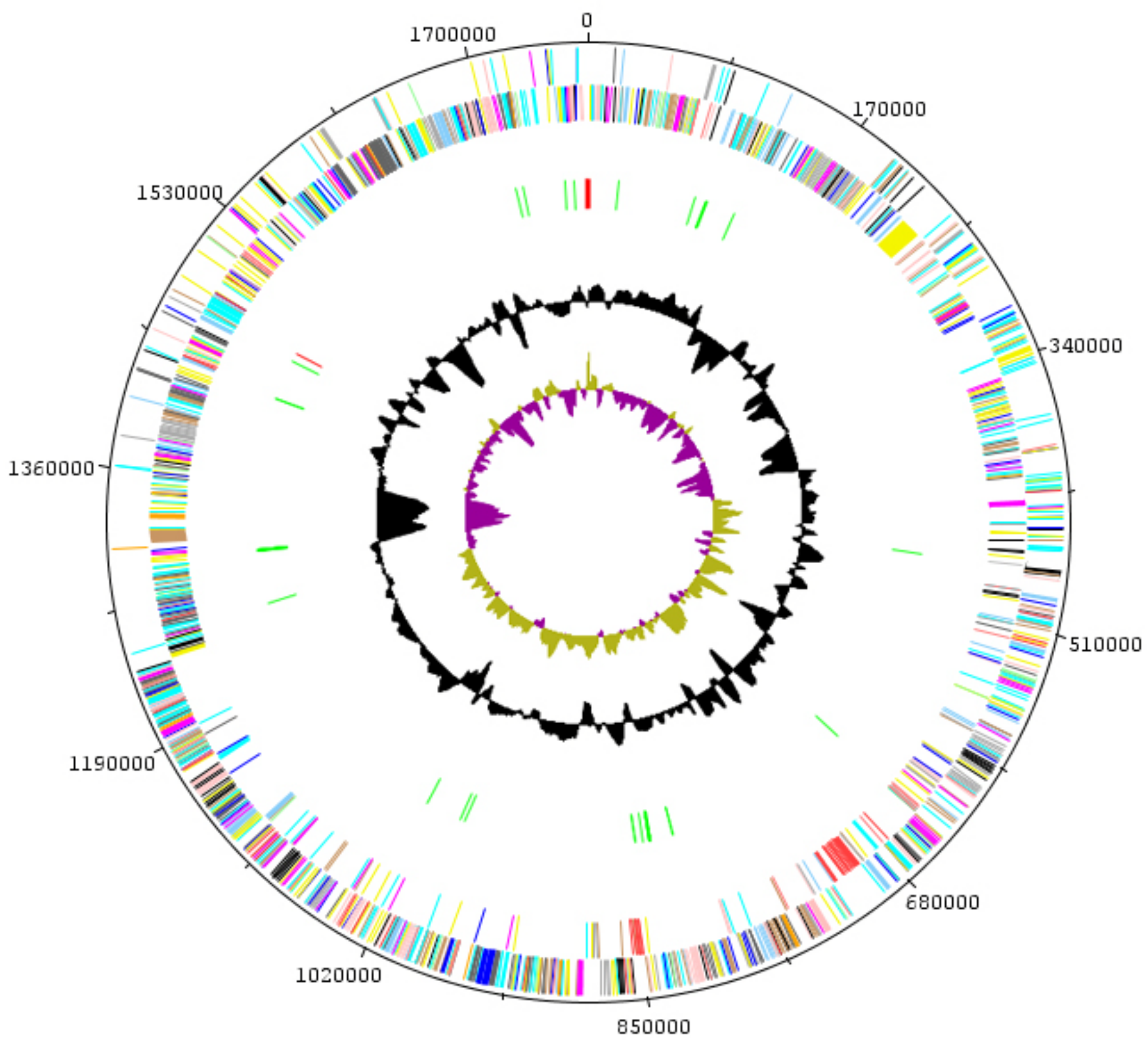

Figure 6. Graphical circular map of the chromosome. From the outside in, the outer two circles show the genes on the forward and reverse directions (colored by COG categories). The third circle marks the rRNA operon in red and tRNA genes in green. The fourth circle shows the $\mathrm{G}+\mathrm{C} \%$ content plot. The inner-most circle shows $\mathrm{GC}$ skew, with purple and olive indicating negative and positive values, respectively. 
Table 4. Nucleotide content and gene count levels of the chromosome

\begin{tabular}{lrr}
\hline Attribute & Value & \% of total $^{\mathbf{a}}$ \\
\hline Genome size (bp) & $1,770,679$ & \\
DNA coding region (bp) & $1,590,528$ & 89.82 \\
DNA G+C content (bp) & 910,129 & 51.40 \\
Total genes & 1,625 & 100 \\
RNA genes & 50 & 3.07 \\
Protein-coding genes & 1,575 & 96.92 \\
Genes with function prediction & 1,238 & 76.18 \\
Genes assigned to COGs & 1,165 & 71.69 \\
Genes with peptide signals & 90 & 5.53 \\
Genes with transmembrane helices & 405 & 24.92 \\
\hline
\end{tabular}

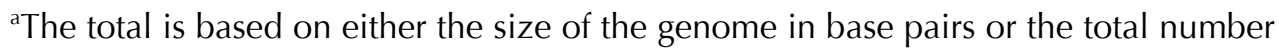
of protein-coding genes in the annotated genome

Table 5. Number of genes associated with the 25 general COG functional categories

\begin{tabular}{crrl}
\hline Code & Value & \% $_{\text {age }} \mathbf{a}$ & Description \\
\hline J & 131 & 4.86 & Translation \\
A & 0 & 0.032 & RNA processing and modification \\
K & 75 & 5.31 & Transcription \\
L & 107 & 5.74 & Replication, recombination and repair \\
B & 0 & 0 & Chromatin structure and dynamics \\
D & 15 & 0.78 & Cell cycle control, mitosis and meiosis \\
Y & 0 & 0 & Nuclear structure \\
V & 51 & 1.53 & Defense mechanisms \\
T & 22 & 1.69 & Signal transduction mechanisms \\
M & 72 & 3.42 & Cell wall/membrane biogenesis \\
N & 1 & 0 & Cell motility \\
Z & 0 & 0 & Cytoskeleton \\
W & 0 & 0 & Extracellular structures \\
U & 13 & 0.84 & Intracellular trafficking and secretion \\
O & 45 & 2.47 & Posttranslational modification, protein turnover, chaperones \\
C & 66 & 4.53 & Energy production and conversion \\
G & 88 & 2.87 & Carbohydrate transport and metabolism \\
E & 67 & 6.16 & Amino acid transport and metabolism \\
F & 47 & 2.05 & Nucleotide transport and metabolism \\
H & 34 & 2.34 & Coenzyme transport and metabolism \\
I & 28 & 4.01 & Lipid transport and metabolism \\
P & 59 & 4.14 & Inorganic ion transport and metabolism \\
Q & 4 & 0.81 & Secondary metabolites biosynthesis, transport and catabolism \\
R & 127 & 8.15 & General function prediction only \\
S & 113 & 5.93 & Function unknown \\
- & 410 & 26.03 & Not in COGs \\
\hline
\end{tabular}

${ }^{\text {aT }}$ The total is based on the total number of protein-coding genes in the annotated genome 


\section{Genomic comparison of $K$. massiliensis and other members of the family}

\section{Clostridiales Incertae Sedis XI.}

Currently, 35 genomes are available for members of the family Clostridiales Incertae Sedis XI. Here, we compared the genome sequence of $K$. massiliensis strain ph2 $2^{\mathrm{T}}$ with those of Finegoldia magna strain ATCC 29328, Helcococcus kunzii strain ATCC 51366, Peptoniphilus indolicus strain ATCC 29427 and Parvimonas micra strain ATCC 33270. The draft genome of $K$. massiliensis $(1.77 \mathrm{Mb})$ is smaller than all other genomes except P. micra $(1.70 \mathrm{Mb})$ and exhibits a higher $\mathrm{G}+\mathrm{C}$ content (51.40) (Table 6A). The gene content of $K$. massiliensis is also lower than the other four genomes used for comparison (Table 6B). In addition, K. massiliensis shared 653, 549, 592 and 548 orthologous genes with F.magna, $H$. kunzii,P. indolicus and P.micra respectively. The average nucleotide sequence identity ranged from 58.61 to 69.17\% among Clostridiales Incertae Sedis XI family species, and from 58.61 to $59.97 \%$ between $K$. massiliensis and other species, thus confirming its new genus status (Table 6B).

Table 6A. Genomic comparison of $K$. massiliensis gen. nov., sp. nov., strain ph2 ${ }^{\top}$ with four other members of the family Clostridiales Incertae Sedis $\mathrm{XI}^{+}$

\begin{tabular}{|c|c|c|c|c|}
\hline Species & Strain & Genome accession number & Genome size $(\mathrm{Mb})$ & $G+C$ content \\
\hline K. massiliensis & $\mathrm{ph} 2^{\top}$ & CAHC00000000 & $1,770,679$ & 51.40 \\
\hline F. magna & ATCC 29328 & NC_010376 & $1,797,577$ & 32.1 \\
\hline H. kunzii & ATCC 51366 & AGEI01000000 & $2,083,191$ & 29.40 \\
\hline P. indolicus & ATCC 29427 & AGBB01000000 & $2,101,630$ & 31.70 \\
\hline P. micra & ATCC 33270 & ABEE02000000 & $1,703,772$ & 28.70 \\
\hline
\end{tabular}

${ }^{\dagger}$ Species and strain names, GenBank genome accession numbers, sizes and G+C contents.

Table 6B. Genomic comparison of $K$. massiliensis gen. nov., sp. nov., strain ph $2^{\top}$ with four other members of the family Clostridiales Incertae Sedis $\mathrm{XI}^{\dagger}$

\begin{tabular}{lrrrrr}
\hline & K. massiliensi & F. magna & H. kunzii & P. indolicus & P. micr \\
\hline K. massiliensis & $\mathbf{1 , 5 6 8}$ & 635 & 549 & 592 & 548 \\
F. magna & 59.22 & $\mathbf{1 , 6 5 6}$ & 629 & 687 & 665 \\
H. kunzii & 59.06 & 68.20 & $\mathbf{1 , 8 7 8}$ & 561 & 560 \\
P. indolicus & 59.97 & 67.98 & 67.57 & $\mathbf{2 , 2 0 5}$ & 615 \\
P. micra & 58.61 & 69.17 & 68.52 & 68.64 & $\mathbf{1 , 5 9 7}$ \\
\hline
\end{tabular}

+ Numbers of orthologous proteins shared between genomes (upper right), average percentage of nucleotide similarity of orthologous proteins shared between genomes (lower left). Bold numbers indicate numbers of proteins per genome. 


\section{Conclusion}

On the basis of phenotypic, phylogenetic and genomic analyses, we formally propose the creation of Kallipya massiliensis gen. nov., sp. nov., that contains the strain ph2 ${ }^{\mathrm{T}}$. This bacterium has been found in France.

\section{Description of Kallipyga gen. nov.}

Kallipyga (cal.li.pi'ga N.L. fem. N. Kallipyga of the Greek epithet kallipygos, said of a statue of Aphrodite having beautifully proportioned buttocks).

Gram-positive cocci. Strictly anaerobic. Mesophilic. Non-Motile. Does not exhibit catalase, oxidase and indole production nor nitrate reduction. Positive for $\alpha$-galactosidase, arginine dihydrolase, arginine arylamidase, and $\alpha-$ and $\beta$ glucosidase. Habitat: human digestive tract. Type species: Kallipyga massiliensis.

\section{Description of Kallipyga massiliensis gen.}

\section{nov., sp. nov.}

Kallipyga massiliensis (mas.il'ien'sis. L. gen. fem. n. massiliensis, of Massilia, the Latin name of Marseille where was cultivated strain ph2 ${ }^{\mathrm{T}}$ ). It has been isolated from the feces of an obese French patient.

Gram-positive cocci. Strictly anaerobic. Mesophilic. Optimal growth at $37^{\circ} \mathrm{C}$. Non-motile and non-sporulating. Colonies are bright grey with $1.0 \mathrm{~mm}$ in diameter on blood-enriched Columbia agar. Cells are cocci with a diameter ranging from $0.57 \mu \mathrm{m}$ to $0.78 \mu \mathrm{m}$ with a mean diameter of 0.67 .

\section{Acknowledgements}

The authors thank the Xegen Company (www.xegen.fr) for automating the genomic annotation process. This

\section{References}

1. Lagier JC, Armougom F, Million M, Hugon P, Pagnier I, Robert C, Bittar F, Fournous G, Gimenez G, Maraninchi M, et al. Microbial culturomics: paradigm shift in the human gut microbiome study. Clin Microbiol Infect 2012; 18:1185-1193. PubMed

2. Dubourg G, Lagier JC, Armougom F, Robert C, Hamad I, Brouqui P. The gut microbiota of a patient with resistant tuberculosis is more comprehensively studied by culturomics than by metagenomics. Eur I Clin Microbiol Infect Dis 2013; 32:637-645. PubMed http://dx.doi.org/10.1007/s10096-012-1787-3
Catalase and oxidase activities are negative. $\mathrm{Ni}$ trate reduction and indole production are absent. Negative reactions were observed for $\beta$ galactosidase, $\beta$-galactosidase- 6 -phosphate, $\alpha$ arabinosidase, $\quad \beta$-glucuronidase, $\quad \mathrm{N}$-acetyl- $\beta$ glucosaminidase, glutamic acid decarboxylase, proline arylamidase, leucyl glycine arylamidase, phenylalanine arylamidase, pyroglutamic acid arylamidase, tyrosine arylamidase, alanine arylamidase, glycine arylamidase, histidine arylamidase, glutamyl glutamic acid arylamidase, and serine arylamidase, mannose and raffinose fermentation, esterase, lipase, valine and cystine arylamidase, trypsine, $\alpha$-chymotrypsine, naphtholAS-BI-phosphohydrolase, $\beta$-galactosidase, $\beta$ Glucuronidase, $\quad \mathrm{N}$-acetyl- $\beta$-glucosaminidase, $\alpha$ mannosidase and $\alpha$-fucosidase. Positive reactions were observed for $\alpha$-galactosidase, arginine dihydrolase and arginine arylamidase, $\alpha$ and $\beta$ glucosidase, esterase lipase, leucine arylamidase and acid phosphatase. Cells weakly oxidized Dribose, D-glucose, D-fructose and aesculin. Cells are susceptible to amoxicillin, amoxicillinclavulanic acid, gentamicin 500, penicillin, imipenem, vancomycin, rifampin and nitrofurantoine. The 16S rRNA and genome sequences are deposited in GenBank under accession numbers JN837487 and CAHC00000000, respectively. The $\mathrm{G}+\mathrm{C}$ content of the genome is $51.40 \%$. The type strain ph2 $2^{\mathrm{T}}(=\mathrm{CSUR}$ P241 = DSM 26229) was isolated from the fecal flora of an obese patient in France.

study was funded by the Mediterranee-Infection Foundation.

3. Pfleiderer A, Lagier JC, Armougom F, Robert C, Vialettes B, Raoult D. Culturomics identified 11 new bacterial species from a single anorexia nervosa stool sample. [Epub ahead of print]. Eur J Clin Microbiol Infect Dis 2013. PubMed http://dx.doi.org/10.1007/s10096-013-1900-2

4. Tindall BJ, Rossello-Mora R, Busse HJ, Ludwig W, Kampfer P. Notes on the characterization of prokaryote strains for taxonomic purposes. Int I Syst Evol Microbiol 2010; 60:249-266. PubMed http://dx.doi.org/10.1099/ijs.0.016949-0 
5. Stackebrandt E, Ebers J. Taxonomic parameters revisited: tarnished gold standards. Microbiol Today 2006; 33:152-155.

6. Wayne LG, Brenner DJ, Colwell RR, Grimont PAD, Kandler O, Krichevsky MI, Moore LH, Moore WEC, Murray RGE, Stackebrandt E, et al. Report of the ad hoc committee on reconciliation of approaches to bacterial systematic. Int / Syst Bacteriol 1987; 37:463-464.

http://dx.doi.org/10.1099/00207713-37-4-463

7. Rossello-Mora R. DNA-DNA Reassociation Methods Applied to Microbial Taxonomy and Their Critical Evaluation. In: Stackebrandt E (ed), Molecular Identification, Systematics, and population Structure of Prokaryotes. Springer, Berlin, 2006; p. 23-50.

8. Welker M, Moore ER. Applications of whole-cell matrix-assisted laser-desorption/ionization timeof-flight mass spectrometry in systematic microbiology. Syst Appl Microbiol 2011; 34:2-11. PubMed http://dx.doi.org/10.1016/j.syapm.2010.11.013

9. Kokcha S, Mishra AK, Lagier JC, Million M, Leroy Q, Raoult D, Fournier PE. Non-contiguous finished genome sequence and description of Bacillus timonensis sp. nov. Stand Genomic Sci 2012; 6:346-355. PubMed http://dx.doi.org/10.4056/sigs.2776064

10. Lagier JC, El Karkouri K, Nguyen TT, Armougom F, Raoult D, Fournier PE. Non-contiguous finished genome sequence and description of Anaerococcus senegalensis sp. nov. Stand Genomic Sci 2012; 6:116-125. PubMed http://dx.doi.org/10.4056/sigs.2415480

11. Mishra AK, Gimenez G, Lagier JC, Robert C, Raoult D, Fournier PE. Non-contiguous finished genome sequence and description of Alistipes senegalensis sp. nov. Stand Genomic Sci 2012; 6:304-314. http://dx.doi.org/10.4056/sigs.2625821

12. Lagier JC, Armougom F, Mishra AK, Ngyuen TT, Raoult D, Fournier PE. Non-contiguous finished genome sequence and description of Alistipes timonensis sp. nov. Stand Genomic Sci 2012; 6:315-324. PubMed

13. Mishra AK, Lagier JC, Robert C, Raoult D, Fournier PE. Non-contiguous finished genome sequence and description of Clostridium senegalense sp. nov. Stand Genomic Sci 2012; 6:386-395. PubMed

14. Mishra AK, Lagier JC, Robert C, Raoult D, Fournier PE. Non-contiguous finished genome se- quence and description of Peptoniphilus

timonensis sp. nov. Stand Genomic Sci 2012; 7:111. PubMed

http://dx.doi.org/10.4056/sigs.2956294

15. Mishra AK, Lagier JC, Rivet R, Raoult D, Fournier $P E$. Non-contiguous finished genome sequence and description of Paenibacillus senegalensis sp. nov. Stand Genomic Sci 2012; 7:70-81. PubMed

16. Lagier JC, Gimenez G, Robert C, Raoult D, Fournier PE. Non-contiguous finished genome sequence and description of Herbaspirillum massiliense sp. nov. Stand Genomic Sci 2012; 7:200-209. PubMed

17. Roux V, El Karkouri K, Lagier JC, Robert C, Raoult $D$. Non-contiguous finished genome sequence and description of Kurthia massiliensis sp. nov. Stand Genomic Sci 2012; 7:221-232. PubMed http://dx.doi.org/10.4056/sigs.3206554

18. Kokcha S, Ramasamy D, Lagier JC, Robert C, Raoult D, Fournier PE. Non-contiguous finished genome sequence and description of Brevibacterium senegalense sp. nov. Stand Genomic Sci 2012; 7:233-245. PubMed http://dx.doi.org/10.4056/sigs.3256677

19. Ramasamy D, Kokcha S, Lagier JC, N'Guyen TT, Raoult D, Fournier PE. Non-contiguous finished genome sequence and description of Aeromicrobium massilense sp. nov. Stand Genomic Sci 2012; 7:246-257. PubMed http://dx.doi.org/10.4056/sigs.3306717

20. Lagier JC, Ramasamy D, Rivet R, Raoult D, Fournier PE. Non-contiguous finished genome sequence and description of Cellulomonas massiliensis sp. nov. Stand Genomic Sci 2012; 7:258-270. PubMed http://dx.doi.org/10.4056/sigs.3316719

21. Lagier JC, El Karkouri K, Rivet R, Couderc C, Raoult D, Fournier PE. Non-contiguous finished genome sequence and description of Senegalemassilia anaerobia sp. nov. Stand Genomic Sci 2013; 7:343-356. http://dx.doi.org/10.4056/sigs.3246665

22. Mishra AK, Hugon $P$, Lagier JC, Nguyen TT, Robert C, Couderc C, Raoult D, Fournier PE. Noncontiguous finished genome sequence and description of Peptoniphilus obesi sp. nov. Stand Genomic Sci 2013; 7:357-369. http://dx.doi.org/10.4056/sigs.32766871

23. Mishra AK, Lagier JC, Nguyen TT, Raoult D, Fournier PE. Non-contiguous finished genome sequence and description of Peptoniphilus senegalensis sp. nov. Stand Genomic Sci 2013; 
7:370-381.

http://dx.doi.org/10.4056/sigs.3366764

24. Lagier JC, El Karkouri K, Mishra AK, Robert C, Raoult D, Fournier PE. Non-contiguous finished genome sequence and description of Enterobacter massiliensis sp. nov. Stand Genomic Sci 2013; 7:399-412. http://dx.doi.org/10.4056/sigs.3396830

25. Hugon P, Ramasamy D, Lagier JC, Rivet R, Couderc C, Raoult D, Fournier PE. Noncontiguous finished genome sequence and description of Alistipes obesi sp. nov. Stand Genomic Sci 2013; 7:427-439. http://dx.doi.org/10.4056/sigs.3336746

26. Mishra AK, Hugon P, Robert C, Couderc C, Raoult D, Fournier PE. Non-contiguous finished genome sequence and description of Peptoniphilus grossensis sp. nov. Stand Genomic Sci 2012; 7:320-330. PubMed

27. Mishra AK, Hugon P, Lagier JC, Nguyen TT, Couderc C, Raoult D, Fournier PE. Non contiguous-finished genome sequence and description of Enorma massiliensis gen. nov., sp. nov., a new member of the Family Coriobacteriaceae. Stand Genomic Sci 2013; 8:290-305. http://dx.doi.org/10.4056/sigs.3426906

28. Ramasamy D, Lagier JC, Gorlas A, Raoult D, Fournier PE. Non contiguous-finished genome sequence and description of Bacillus massiliosenegalensis sp. nov. Stand Genomic Sci 2013; 8:264-278. http://dx.doi.org/10.4056/sigs.3496989

29. Ramasamy D, Lagier JC, Nguyen TT, Raoult D, Fournier PE. Non contiguous-finished genome sequence and description of of Dielma fastidiosa gen. nov., sp. nov., a new member of the Family Erysipelotrichaceae. Stand Genomic Sci 2013; 8:336-351. http://dx.doi.org/10.4056/sigs.3567059

30. Mishra AK, Lagier JC, Robert C, Raoult D, Fournier PE. Genome sequence and description of Timonella senegalensis gen. nov., sp. nov., a new member of the suborder Micrococcinae. Stand Genomic Sci 2013; 8:318-335. http://dx.doi.org/10.4056/sigs.3476977

31. Garrity GM, Holt JG. Taxonomic outline of the Archae and Bacteria. In: Garrity GM, Boone DR, Castenholz RW (eds), Bergey's Manual of Systematic Bacteriology, second edition, Volume, Springer-Verlag, New York, 2001; p. 155-166.

32. Ezaki T, Kawamura Y, Li N, Li ZY, Zhao L, Shu S. Proposal of the genera Anaerococcus gen. nov.,
Peptoniphilus gen. nov. and Gallicola gen. nov. for members of the genus Peptostreptococcus. Int J Syst Evol Microbiol 2001; 51:1521-1528. PubMed

33. Takii S, Hanada S, Tamaki H, Ueno Y, Sekiguchi Y, Ibe A, Matsuura K. Dethiosulfatibacter aminovorans gen. nov., sp. nov., a novel thiosulfate-reducing bacterium isolated from coastal marine sediment via sulfate-reducing enrichment with Casamino acids. Int I Syst Evol Microbiol 2007; 57:2320-2326. PubMed http://dx.doi.org/10.1099/ijs.0.64882-0

34. Murdoch DA, Shah HN. Reclassification of Peptostreptococcus magnus (Prevot 1933) Holdeman and Moore 1972 as Finegoldia magna comb. nov. and Peptostreptococcus micros (Prevot 1933) Smith 1957 as Micromonas micros comb. nov. Anaerobe 1999; 5:555-559. http://dx.doi.org/10.1006/anae.1999.0197

35. Collins MD, Facklam RR, Rodrigues UM, Ruoff KL. Phylogenetic analysis of some Aerococcuslike organisms from clinical sources: description of Helcococcus kunzii gen. nov., sp. nov. Int J Syst Bacteriol 1993; 43:425-429. PubMed http://dx.doi.org/10.1099/00207713-43-3-425

36. Tindall BJ, Euzeby JP. Proposal of Parvimonas gen. nov. and Quatrionicoccus gen. nov. as replacements for the illegitimate, prokaryotic, generic names Micromonas Murdoch and Shah 2000 and Quadricoccus Maszenan et al. 2002, respectively. Int J Syst Evol Microbiol 2006; 56:2711-2713. PubMed http://dx.doi.org/10.1099/ijs.0.64338-0

37. Breitenstein A, Wiegel J, Haertig C, Weiss N, Andreesen JR, Lechner U. Reclassification of Clostridium hydroxybenzoicum as Sedimentibacter hydroxybenzoicus gen. nov., comb. nov., and description of Sedimentibacter saalensis sp. nov. Int / Syst Evol Microbiol 2002; 52:801-807. PubMed http://dx.doi.org/10.1099/ijs.0.01998-0

38. Parshina SN, Kleerebezem R, Sanz JL, Lettinga G, Nozhevnikova AN, Kostrikina NA, Lysenko AM, Stams AJ. Soehngenia saccharolytica gen. nov., sp. nov. and Clostridium amygdalinum sp. nov., two novel anaerobic, benzaldehyde-converting bacteria. Int I Syst Evol Microbiol 2003; 53:17911799. PubMed http://dx.doi.org/10.1099/ijs.0.02668-0

39. Hernandez-Eugenio G, Fardeau ML, Cayol JL, Patel BK, Thomas P, Macarie H, Garcia JL, Ollivier B. Sporanaerobacter acetigenes gen. nov., sp. nov., a novel acetogenic, facultatively 
Kallipyga massiliensis gen. nov., sp. nov.

sulfur-reducing bacterium. Int J Syst Evol Microbiol 2002; 52:1217-1223. PubMed http://dx.doi.org/10.1099/ijs.0.01992-0

40. Collins MD, Shah HN. Reclassification of Bacteroides praeacutus Tissier (Holdeman and Moore) in a new genus, Tissierella, as Tissierella praeacuta comb. nov. Int / Syst Bacteriol 1986; 36:461-463. http://dx.doi.org/10.1099/00207713$\underline{36-3-461}$

41. List of Prokaryotic names with standing nomenclature (LPSN). http://www.bacterio.cict.fr.

42. Jain S, Bui V, Spencer C, Yee L. Septic arthritis in a native joint due to Anaerococcus prevotii. J Clin Pathol 2007; 61:775-776. PubMed http://dx.doi.org/10.1136/jcp.2007.053421

43. Ulger-Toprak N, Liu C, Summanen PH, Finegold SM. Murdochiella asaccharolytica gen. nov., sp. nov., a Gram-stain-positive, anaerobic coccus isolated from human wound specimens. Int I Syst Evol Microbiol 2010; 60:1013-1016. PubMed http://dx.doi.org/10.1099/ijs.0.015909-0

44. Labutti K, Pukall R, Steenblock K, Glavina Del Rio T, Tice H, Copeland A, Cheng JF, Lucas S, Chen F, Nolan M, et al. Complete genome sequence of Anaerococcus prevotii type strain (PC1). Stand Genomic Sci 2009; 1:159-165. PubMed http://dx.doi.org/10.4056/sigs.24194

45. Veloo AC, Erhard M, Welker M, Welling GW, Degener JE. Identification of Gram-positive anaerobic cocci by MALDI-TOF mass spectrometry. Syst Appl Microbiol 2011; 34:58-62. PubMed http://dx.doi.org/10.1016/j.syapm.2010.11.005

46. Pépin J, Deslandes S, Giroux G, Sobela F, Khonde N, Diakite S, Demeule S, Labbe AC, Carrier N, Frost $\mathrm{E}$. The complex vaginal flora of West African women with bacterial vaginosis. PLOS ONE 2011; 6:e25082. PubMed http://dx.doi.org/10.1371/journal.pone.0025082

47. Woese CR, Kandler O, Wheelis ML. Towards a natural system of organisms: proposal for the domains Archae, Bacteria, and Eukarya. Proc Natl Acad Sci USA 1990; 87:4576-4579. PubMed http://dx.doi.org/10.1073/pnas.87.12.4576

48. Gibbons NE, Murray RGE. Proposals Concerning the Higher Taxa of Bacteria. Int I Syst Bacteriol 1978; 28:1-6. http://dx.doi.org/10.1099/00207713-28-1-1

49. Garrity GM, Holt JG. The Road Map to the Manual. In: Garrity GM, Boone DR, Castenholz RW (eds), Bergey's Manual of Systematic Bacteriolo- gy, Second Edition, Volume 1, Springer, New York, 2001, p. 119-169.

50. Murray RGE. The Higher Taxa, or, a Place for Everything...? In: Holt JG (ed), Bergey's Manual of Systematic Bacteriology, First Edition, Volume 1, The Williams and Wilkins Co., Baltimore, 1984, p. 31-34.

51. List of new names and new combinations previously effectively, but not validly, published. List no. 132. Int J Syst Evol Microbiol 2010; 60:469472. http://dx.doi.org/10.1099/ijs.0.022855-0

52. Rainey FA. Class II. Clostridia class nov. In: De Vos P, Garrity G, Jones D, Krieg NR, Ludwig W, Rainey FA, Schleifer KH, Whitman WB (eds), Bergey's Manual of Systematic Bacteriology, Second Edition, Volume 3, Springer-Verlag, New York, 2009, p. 736

53. Skerman VBD, Sneath PHA. Approved list of bacterial names. Int J Syst Bact 1980; 30:225-420. http://dx.doi.org/10.1099/00207713-30-1-225

54. Prevot AR. In: Hauduroy P, Ehringer G, Guillot G, et al.(eds.), Dictionnaire des bactéries pathogènes, Second Edition, Masson, Paris, 1953, p. 1-692.

55. Garrity GM, Holt J. Taxonomic outline of the Archaea and Bacteria. In: Garrity GM, Boone DR, Castenholz RW (eds.), Bergey's Manual of Systematic Bacteriology, Second Edition, SpringerVerlag, New York, 2003, p.155-166.

56. Ashburner M, Ball CA, Blake JA, Botstein D, Butler H, Cherry JM, Davis AP, Dolinski K, Dwight SS, Eppig JT, et al. Gene ontology: tool for the unification of biology. The Gene Ontology Consortium. Nat Genet 2000; 25:25-29. PubMed http://dx.doi.org/10.1038/75556

57. Benson DA, Karsch-Mizrachi I, Clark K, Lipman DJ, Ostell J, Sayers EW. GenBank. Nucleic Acids Res 2012; 40:D48-D53. PubMed http://dx.doi.org/10.1093/nar/gkr1202

58. Kong HH, Grice EA, Conlan $\mathrm{S}$, Deming CB, Freeman AF, Beatson $M$, Nomicos $E$, Young AC, Bouffard GG, Blakesley RW, et al. Temporal shifts in the skin microbiome associated with disease flares and treatment in children with atopic dermatitis. Genome Res 2012; 22:850-859. PubMed http://dx.doi.org/10.1101/gr.131029.111

59. Seng P, Drancourt M, Gouriet F, La SB, Fournier $\mathrm{PE}$, Rolain JM, et al. Ongoing revolution in bacteriology: routine identification of bacteria by matrix-assisted laser desorption ionization time-offlight mass spectrometry. Clin Infect Dis 2009; 
49:543-551. PubMed

http://dx.doi.org/10.1086/600885

60. Field D, Garrity G, Gray T, Morrison N, Selengut J, Sterk P, Tatusova T, Thomson N, Allen MJ, Angiuoli SV, et al. The minimum information about a genome sequence (MIGS) specification. Nat Biotechnol 2008; 26:541-547. PubMed http://dx.doi.org/10.1038/nbt1360

61. Prodigal. http://prodigal.ornl.gov/

62. Lowe TM, Eddy SR. tRNAscan-SE: a program for improved detection of transfer RNA genes in genomic sequence. Nucleic Acids Res 1997;

25:955-964. PubMed

63. Lagesen K, Hallin P, Rodland EA, Staerfeldt HH, Rognes T, Ussery DW. RNAmmer: consistent and rapid annotation of ribosomal RNA genes. Nucleic Acids Res 2007; 35:3100-3108. PubMed http://dx.doi.org/10.1093/nar/gkm160

64. Bendtsen JD, Nielsen H, von Heijne G, Brunak S. Improved prediction of signal peptides: SignalP 3.0. J Mol Biol 2004; 340:783-795. PubMed http://dx.doi.org/10.1016/j.jmb.2004.05.028

65. Krogh A, Larsson B, von Heijne G, Sonnhammer EL. Predicting transmembrane protein topology with a hidden Markov model: application to complete genomes. J Mol Biol 2001; 305:567580. $\underline{\text { PubMed }}$

http://dx.doi.org/10.1006/jmbi.2000.4315

66. Rutherford K, Parkhill J, Crook J, Horsnell T, Rice $P$, Rajandream MA, Barrell B. Artemis: sequence visualization and annotation. Bioinformatics 2000; 16:944-945. PubMed http://dx.doi.org/10.1093/bioinformatics/16.10.94 $\underline{4}$

67. Carver T, Thomson N, Bleasby A, Berriman M, Parkhill J. DNAPlotter: circular and linear interactive genome visualization. Bioinformatics 2009; 25:119-120. PubMed http://dx.doi.org/10.1093/bioinformatics/btn578

68. Darling AC, Mau B, Blattner FR, Perna NT. Mauve: multiple alignment of conserved genomic sequence with rearrangements. Genome Res 2004; 14:1394-1403. PubMed http://dx.doi.org/10.1101/gr.2289704

69. Lechner M, Findeib S, Steiner L, Marz M, Stadler PF, Prohaska SJ. Proteinortho: Detection of (Co)orthologs in large-scale analysis. BMC Bioinformatics $2011 ; 12: 124$. PubMed http://dx.doi.org/10.1186/1471-2105-12-124 